\title{
Clinical Characteristics of Auricular Keloids Treated with Surgical Excision
}

\author{
So Young Park, Guen-Ho Lee, Jung Mee Park, Sang-Gyun Jin and Jeong-Hoon Oh \\ Department of Otolaryngology-Head and Neck Surgery, College of Medicine, The Catholic University of Korea, Seoul, Korea
}

Received November 23, 2012

Revised December 3,2012

Accepted December 5, 2012

Address for correspondence
Jeong-Hoon Oh, MD
Department of Otolaryngology-
Head and Neck Surgery,
College of Medicine,
The Catholic University of Korea,
St. Paul's Hospital, 180 Wangsan-ro,
Dongdaemun-gu, Seoul 130-709,
Korea
Tel+82-2-961-4531
Fax+82-2-959-5375
E-mail ojhent@catholic.ac.kr

Background and Objectives: Differences in morphology of auricular keloids possibly contribute to distinct results of treatment. The aim of this study was to evaluate clinical characteristics of the auricular keloids according to the modified Chang-Park classification and to compare the results of treatment including recurrence rate between the subgroups. Subjects and Methods: Clinical data of 15 patients of auricular keloids were retrospectively reviewed. The keloids were classified according to modified Chang-Park classification. Clinical characteristics, the presence of recurrence, and the duration required for the recurrence were compared. Results: Eight out of 15 patients (53.3\%) were single sessile type (type II), followed by 4 patients of pedunculated type, 1 patient of multiple sessile type, 1 patient of buried type, and 1 patient of mixed type, respectively. Recurrent keloids after previous surgeries were noted in 7 out of 15 patients and most of them (6 of 7,85.7\%) were sessile type. Three patients who underwent surgery at our department showed recurrence. Conclusions: The classification of auricular keloids according to morphologic patterns can assist surgeons in choosing the appropriate management.

Korean J Audiol 2012;16:134-137

KEY WORDS: Keloid · Auricle · Classification · Treatment.

\section{Introduction}

When injured, the skin must consistently and rapidly repair itself in order to maintain its external defense system. The result of wound healing is the formation of a scar at the site of tissue disruption. The rate and quality of scar formation vary among the individuals, and the alterations in this process may result in the development of a chronic wound or an abnormal scar. Keloids are hypertrophic-appearing scars that continue to evolve over time without a quiescent or regressive phase in the process of wound healing. ${ }^{1,2)}$ Keloids infiltrate into surrounding normal tissue and rarely regress so that they continue to evolve over time. ${ }^{3,4)}$ Especially in the head and neck region, these lesions are conspicuous and the patients typically present with cosmetic concerns. Earlobes and helix of the auricle are common sites for keloid formation usually after a trauma or ear piercing, with an incidence of approximately $2.5 \%{ }^{5}{ }^{5)}$ The treatment options are still controversial despite numerous challenges and any single best treatment or combination of treatments has not been proved to manage these conditions effectively. Furthermore, there is only a little morpho- logic classification for the auricular keloids. ${ }^{6}$

The aim of this study was to evaluate clinical characteristics of the auricular keloids according to the modified Chang-Park classification, ${ }^{6}$ which was originally developed for the classification of earlobe keloids, and to compare the results of treatment including recurrence rate between the subgroups.

\section{Subjects and Methods}

A retrospective chart review was performed from March 2007 to February 2011. Data from the patients who underwent surgical excision with steroid injection therapy for the treatment of auricular keloids at St. Paul's hospital was analyzed. The keloids were classified as sessile or pedunculated according to the degree of surface contact with normal auricular skin (Table 1, Fig. 1). ${ }^{6}$ The sessile keloids were defined if the length of contact surface between the mass and the normal skin exceeded two-thirds of the longest diameter of the mass. They were further classified into subgroups according to the presence of conglomeration in a single nodular type (Type II) or in a multi-nodular type (Type III). Clinical characteristics in- 
Table 1. Modified Chang-Park classification to classify auricular keloids according to the morphology ${ }^{6)}$

\begin{tabular}{|c|c|c|}
\hline Classification & Type & Description \\
\hline Type I & Pedunculated & $\begin{array}{l}\text { Longest diameter of the mass contact surface with the normal auricular skin is less } \\
\text { than } 2 / 3 \text { of the maximal diameter }\end{array}$ \\
\hline Type ॥ & Sessile, single & Sessile-type with a single nodular pattern \\
\hline Type III & Sessile, multiple & Sessile-type with a multi-nodular pattern \\
\hline Type IV & Buried & Minimal to mild contour changes without discoloration \\
\hline Type V & Mixed & $\begin{array}{l}\text { More than } 80 \% \text { has buried type anterior surface and pedunculated type at the } \\
\text { posterior surface }\end{array}$ \\
\hline
\end{tabular}

Fig. 1. Preoperative photographs of type I (pedunculated) (A) and type II (sessile) (B) helical keloids.
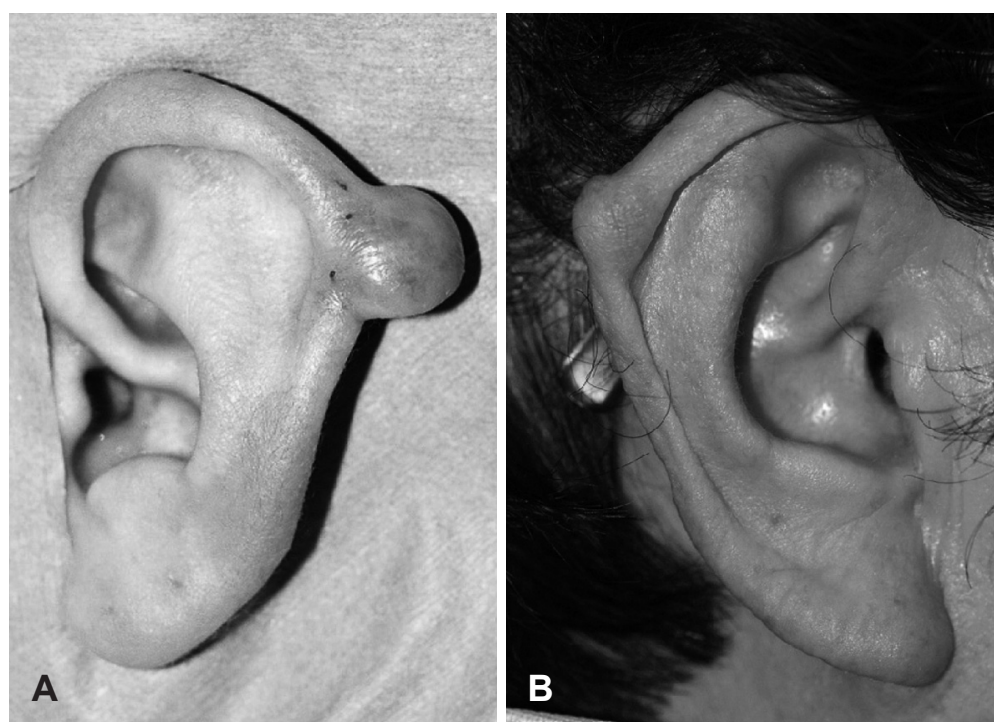

cluding demographic features (gender, age, laterality and follow-up period), the presence of recurrence, and the duration required for the recurrence were compared between the subgroups.

\section{Results}

One male and 14 female patients (mean age 32.3 \pm 16.2 years) were enrolled in this study. Average follow-up period was $35.5 \pm 22.2$ months with the longest follow-up interval of 5 years. Nine patients had keloids on earlobe, and six patients had helical keloids. Pre- or retro-auricular keloids were not observed. The etiologies of keloids were ear piercing, trauma, or idiopathic. 8 out of 15 patients $(53.3 \%)$ were single sessile type (Type II), followed by 4 patients $(26.7 \%)$ of pedunculated type (Type I), 1 patient of multiple sessile type (Type III), 1 patient of buried type (Type IV), and 1 patient of mixed type (Type V), respectively (Table 2). Recurrent keloids after previous surgeries were 7 out of 15 patients and most of them ( 6 of 7, 85.7\%) were sessile type (Type II)(Table 2). Average period between the development and the surgery in primary keloids was 14.3 months and 9.8 months in recurrent keloids.

All auricular keloids less than $1.5 \mathrm{~cm}$ were treated by com- plete excision with a primary wound closure and an injection of triamcinolone (Fig. 1A). Larger keloids were treated by wedge excision with Burow's triangles in helical keloids (Fig. 1B), whereas earlobe keloids were treated by excision and reconstruction with a bilobed flap (Fig. 2). 3 out of 15 patients treated at our department showed a recurrence of the keloid. Among them, two developed small indentations within 6 months, whereas the other developed a larger keloid mass two years after the surgical excision. The patient is currently receiving cryotherapy and triamcinolone injections repeatedly.

\section{Discussion}

The purpose of the Chang-Park classification was to improve the understanding of earlobe keloids and to match them with the proper surgical approaches. ${ }^{6}$ According to Park, et al., ${ }^{6}$ a proper selection of surgical methods depends on the gross appearance of the keloid. Appropriate classification that defines various appearance of the keloid mass and classifies the relationship between normal skin structure and the mass can help to determine proper surgical method and to predict outcome at long term follow-up. As the auricle has complex 3D structure with relatively scanty subcutaneous tissue, different sur- 

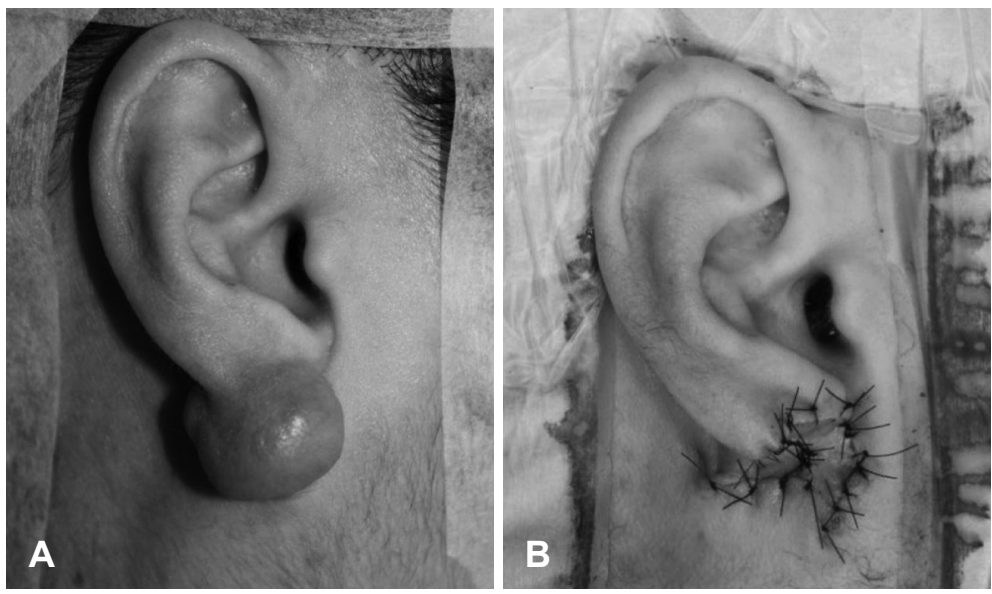

Fig. 2. Preoperative (A) and intraoperative (B) photographs of type II (sessile) earlobe keloid.

Table 2. Localization, size and the presence of recurrence according to Chang-Park classification

\begin{tabular}{|c|c|c|c|c|c|c|c|c|}
\hline \multirow[t]{2}{*}{ Classification } & \multirow{2}{*}{$\begin{array}{l}\text { No. of } \\
\text { patients }\end{array}$} & \multicolumn{2}{|c|}{ Location } & \multirow[t]{2}{*}{ Size $(\mathrm{cm})$} & \multicolumn{2}{|c|}{$\begin{array}{l}\text { No. of recurrence } \\
\text { after previous surgery }\end{array}$} & \multicolumn{2}{|c|}{$\begin{array}{l}\text { Location of recurrence } \\
\text { after latest surgery }\end{array}$} \\
\hline & & Earlobe & Helix & & Primary & Recurrent & Earlobe & Helix \\
\hline Type I & 4 & 2 & 2 & $1.7 \times 1.2$ & 3 & 1 & & \\
\hline Type II & 8 & 5 & 3 & $2.2 \times 1.4$ & 2 & 6 & 2 & 1 \\
\hline Type III & 1 & 1 & & $1.0 \times 0.8$ & 1 & & & \\
\hline Type IV & 1 & 1 & & $2.0 \times 1.0$ & 1 & & & \\
\hline Type V & 1 & & 1 & $0.3 \times 0.3$ & 1 & & & \\
\hline
\end{tabular}

gical approaches to the respective locations and dimensions of the keloids in the auricle are required. In our study, all auricular keloids less than $1.5 \mathrm{~cm}$ were treated by complete excision with primary closure, following an injection of triamcinolone. As in the tumorous condition of the auricle, a large mass requires an additional reconstruction method to maintain auricular shape. In the helix, a complete removal using wedge excision with Burow's triangles was performed, whereas a bilobed flap was used to reconstruct lower auricular structure in an earlobe keloid.

Sometimes simple total excision of a keloid stimulates an additional collagen synthesis, thus prompting quick recurrence of a keloid even larger than the initial one. ${ }^{7,8)}$ Surgical excision of a keloid alone is associated with a high recurrence rate, ${ }^{9-11)}$ and therefore, it should be combined with adjuvant therapy such as pressure, corticosteroids, and radiotherapy. ${ }^{1,11,12)}$ Intralesional corticosteroid injections have become a mainstay in the treatment of keloids, alone or in combination with surgery. ${ }^{13)}$ Corticosteroid decreases fibroblast proliferation, collagen synthesis, and glycosaminoglycan synthesis, and suppresses pro-inflammatory mediators. ${ }^{14)}$ It can be used as the first-line option or combined with the surgery as postoperative adjuvant therapy. Kauh, et al. ${ }^{15)}$ demonstrated that surgical excision combined with a steroid injection into the wound bed causes down-regulation of type I collagen gene expression without compromising wound healing. In our insti- tution, combined injection of triamcinolone at the time of surgery has been performed for the auricular keloids and showed relatively low recurrence rate ( 3 of $15,20 \%)$ comparable to previous reports $\left(9-50 \%\right.$ ) (Table 2). ${ }^{16,17)}$ Another numerous alternative methods, including pressure therapy, cryotherapy, laser treatment, topical silicone gel sheeting, verapa-mil, 5-fluorouracil, bleomycin, interferon alpha- $2 b$, botulinum toxin type A, and colchicine, have been proposed for adjuvant therapy after a surgical excision for the refractory cases. ${ }^{6,18)}$

The main limitation of our study is the small sample size of each classification type, the small number of treatment modalities, and the retrospective analysis method. Although it seems that sessile type keloids were highly related to the recurrence, statistical analysis was not performed because of small sample size. A large prospective randomized trial and multi-center study capable of variable treatment modalities would be necessary in further evaluations.

\section{Conclusion}

The classification of auricular keloids according to morphologic patterns can assist surgeons in choosing the appropriate management. Sessile type keloids demonstrated larger growth and frequent recurrence than the other types. A better understanding of pathophysiology will help to develop more specific therapies for treating and preventing problem scars. 


\section{REFERENCES}

1) Slemp AE, Kirschner RE. Keloids and scars: a review of keloids and scars, their pathogenesis, risk factors, and management. Curr Opin Pediatr 2006;18:396-402.

2) English RS, Shenefelt PD. Keloids and hypertrophic scars. Dermatol Surg 1999;25:631-8.

3) Nemeth AJ. Keloids and hypertrophic scars. J Dermatol Surg Oncol 1993;19:738-46.

4) Murray JC. Scars and keloids. Dermatol Clin 1993;11:697-708.

5) Zuber TJ, DeWitt DE. Earlobe keloids. Am Fam Physician 1994;49: 1835-41.

6) Park TH, Seo SW, Kim JK, Chang CH. Earlobe keloids: classification according to gross morphology determines proper surgical approach. Dermatol Surg 2012;38:406-12.

7) Datubo-Brown DD. Keloids: a review of the literature. Br J Plast Surg 1990;43:70-7.

8) Salasche SJ, Grabski WJ. Keloids of the earlobes: a surgical technique. J Dermatol Surg Oncol 1983;9:552-6.

9) Brown LA Jr, Pierce HE. Keloids: scar revision. J Dermatol Surg Oncol 1986;12:51-6.

10) Kischer CW, Shetlar MR, Chvapil M. Hypertrophic scars and keloids: a review and new concept concerning their origin. Scan Electron Microsc 1982;(Pt 4):1699-713.
11) Wolfram D, Tzankov A, Pülzl P, Piza-Katzer H. Hypertrophic scars and keloids--a review of their pathophysiology, risk factors, and therapeutic management. Dermatol Surg 2009;35:171-81.

12) Juckett G, Hartman-Adams H. Management of keloids and hypertrophic scars. Am Fam Physician 2009;80:253-60.

13) Golladay ES. Treatment of keloids by single intraoperative perilesional injection of repository steroid. South Med J 1988;81:736-8.

14) Urioste SS, Arndt KA, Dover JS. Keloids and hypertrophic scars: review and treatment strategies. Semin Cutan Med Surg 1999;18:15971.

15) Kauh YC, Rouda S, Mondragon G, Tokarek R, diLeonardo M, Tuan RS, et al. Major suppression of pro-alpha1(I) type I collagen gene expression in the dermis after keloid excision and immediate intrawound injection of triamcinolone acetonide. J Am Acad Dermatol 1997;37: 586-9.

16) Niessen FB, Spauwen PH, Schalkwijk J, Kon M. On the nature of hypertrophic scars and keloids: a review. Plast Reconstr Surg 1999;104: 1435-58.

17) Gauglitz GG, Korting HC, Pavicic T, Ruzicka T, Jeschke MG. Hypertrophic scarring and keloids: pathomechanisms and current and emerging treatment strategies. Mol Med 2011;17:113-25.

18) Music EN, Engel G. Earlobe keloids: a novel and elegant surgical approach. Dermatol Surg 2010;36:395-400. 